\title{
> Cinema e fotografia: as técnicas e suas ambiguidades em Benjamin, Flusser e Agamben
}

\author{
> Cinema and photography: the techniques and their ambiguities in \\ Benjamin, Flusser and Agamben
}

\begin{abstract}
por Sônia Campaner Miguel Ferrari
Prof. ${ }^{a}$ Dr. ${ }^{a}$. do departamento de Filosofia da PUCSP, pesquisa nas áreas de Estética e Filosofia da Arte, e as relações entre Ética e Política. E-mail: soniacamp@pucsp.br. ORCID: 0000-0002-4862-0183
\end{abstract}

\section{Resumo}

O objetivo deste artigo é o de apresentar as concepções acerca das técnicas de Walter Benjamin, Vilém Flusser e Giorgio Agamben. No ensaio sobre a obra de arte Benjamin reflete sobre o cinema e as mudanças que a nova técnica introduz não só na concepção e função da arte na modernidade, mas também na percepção. Para ele as mudanças produzem uma reordenação da percepção e introduzem novas formas de sentir e perceber o mundo que correspondem a esse mundo. Portanto não há porque considerar essas mudanças como positivas ou negativas. As reflexões de Flusser são apresentadas a partir de seu Filosofia da caixa preta, em que o autor toma o fenômeno fotográfico para fazer um diagnóstico sobre a sociedade contemporânea, e que será estendido às outras técnicas em O Universo das imagens técnicas. A visão inicialmente pessimista de Flusser é nuançada nesta última obra. Agamben parece encontrar-se no ponto médio entre os dois pensadores ao definir o dispositivo, e o processo de profanação para combatê-lo.

Palavras-chave: Técnica. Dispositivo. Aparato. Cinema. Fotografia.

\begin{abstract}
The purpose of this article is to present the conceptions about the techniques of the following authors: Walter Benjamin, Vilém Flusser and Giorgio Agamben.In the essay on the work of art Benjamin reflects on the cinema and the changes that the new technique introduce not only in the conception and function of art in modernity but also in perception. For him the changes produce a reordering of perception and introduce new ways of feeling and perceiving the world that correspond to this world. So there is no reason to consider these changes as positive or negative. Flusser's reflections are presented from his book Philosophy of Photography, in which the author takes the photographic phenomenon to make a diagnosis of contemporary society, and which will be extended to other techniques in Into the universe of technical images. His initially pessimistic view is nuanced in this latest work. Agamben seems to find himself midway between the two thinkers when he defines the dispositor, and the profanation process to combat it.
\end{abstract}

Keywords: Technique. Dispositor. Apparatus. Cinema. Photography. 


\section{Benjamin e o cinema}

No ensaio sobre a obra de arte ${ }^{1}$, Benjamin compara seu texto com O Capital de Marx, pois este último "orientou suas investigações de forma a dar-lhes valor de prognósticos". Sua análise da forma mercadoria tinha naquele momento o sentido de apontar a direção na qual o capitalismo avançava: no sentido de promover uma maior exploração do proletariado, e também de preparar o seu próprio fim.

Para Benjamin, o ano de 1935 se apresenta como um momento oportuno para novos prognósticos, desta vez calcados sobre o modo como as condições de produção analisadas por Marx evoluíram de maneira a refletir-se em todas as esferas da cultura. À diferença da análise marxiana, cujos prognósticos levaram meio século para poderem ser observados, e que em parte se referiam à produção da arte revolucionária, os prognósticos de Benjamin mencionam as "tendências evolutivas da arte"2, e podem ser observados imediatamente.

São esses prognósticos que nos interessam: prognósticos que afirmam a transformação da arte e de sua função que apontam para a perda da transcendência e da aura ${ }^{3}$ da obra de arte, mas que ao mesmo tempo levantam possibilidades nas quais a arte não deixa de existir e ter um papel, e nas quais podemos identificar o fenômeno do deslocamento da aura.

Toda forma de arte amadurecida, nos diz Benjamin, está no ponto de intersecção de três linhas evolutivas ${ }^{4}: 1$ ) a atuação da técnica sobre uma forma de arte; 2) a realização, pela nova forma de arte, dos efeitos que as formas tradicionais

\footnotetext{
${ }^{1}$ Walter Benjanim, A obra de arte na era de sua reprodutibilidade técnica, 1985.

${ }^{2}$ Walter Benjamin, Gesammelte Schriften, 1980, p. 435; A obra de arte na era de sua reprodutibilidade técnica, 1985, p. 166. As citações de Walter Benjamin serão feitas deste modo: em primeiro lugar a página correspondente à edição em língua alemã, e em segundo lugar a página correspondente à tradução brasileira.

${ }^{3}$ O conceito de aura aparece em Benjamin principalmente no texto referido na nota 1. Textualmente ele diz: a aura "é uma figura singular, composta de elementos espaciais e temporais: a aparição única de uma coisa distante, por mais perto que esteja" (Ibidem, 1985, p. 170). As formas de reprodução técnica ameaçam a sua existência.

${ }^{4}$ Ibidem, 1980, p. 456-7; ibidem, 1985, p. 185.
} 
de arte tentaram produzir; 3) a produção e utilização de mudanças nas estruturas da percepção pelas novas formas de arte. ${ }^{5}$ Essas três linhas estão também relacionadas com a influência das novas técnicas na produção e recepção da arte.

A primeira linha remete às relações da técnica com as artes antes existentes. É inegável que fotografia e o cinema criaram condições novas para a recepção das artes, mesmo que estas não absorvam características relacionadas às técnicas modernas. Olhar para uma pintura tornou-se algo que se faz de um modo distinto do modo contemplativo. Significa que as novas técnicas interferem no modo como a arte é percebida e produzida. Mesmo que visitemos um museu no qual se encontram obras produzidas em momentos em que a arte tinha função ritual, cuja autenticidade estava relacionada a um fundamento teológico, ou função de registro (retratos e pinturas históricas), o modo de recepção dessa arte se dá de maneira análoga às imagens produzidas pela fotografia, ou pelo cinema, isto é, de maneira dispersa.

Adorno, no texto Fetichismo na música e regressão da audição ${ }^{6}$, afirma que a presença da indústria na cena cultural produziu um público incapaz de manterse contemplativo ao ver uma pintura ou ouvir uma música. $\mathrm{O}$ jazz, objeto de sua crítica, mudou a qualidade da audição do público. Benjamin, no entanto, entende que essa influência pode não ser tão deletéria, pois torna o público mais atento ao que está à sua volta, tornando-o mais apto para a vida numa cidade moderna.

A segunda linha refere-se ao desenvolvimento técnico como uma forma de realizar desejos utópicos, antes expressos em formas ainda rudimentares ou por meio de técnicas que apenas projetavam tal desejo sem realizá-lo. Por exemplo, o desejo de exprimir o movimento só foi realizado pelo cinema. A relação entre o desenvolvimento técnico e desejos utópicos aparece na versão francesa do texto. ${ }^{7}$ Ali Benjamin relaciona o gesto da humanidade em direção ao desenvolvimento

\footnotetext{
${ }^{5}$ Ibidem, 1980, p. 457-8; ibidem, 1985, p. 185.

6 Theodor Adorno, Fetichismo na música e regressão da audição, 1975.

${ }^{7}$ Walter Benjamin, Gesammelte Schriften, 1980, p. 717.
} 
técnico com o gesto da criança que busca alcançar a lua. Com tais gestos, a humanidade busca alcançar, além dos fins acessíveis, outros que são utópicos. ${ }^{8}$

A terceira linha remete tanto à recepção da obra de arte contemporânea quanto ao fato de que essa mesma arte (além de outros meios) produz as condições nas quais ela deverá ser recebida pelo público. Ainda, ela é um produto da modernidade e da modernização. ${ }^{9}$ Benjamin associa cinema e arquitetura, duas formas de arte cuja recepção se dá de maneira dispersa e coletiva. O motivo disso é que as obras cinematográficas e arquitetônicas adequam-se ao formato de uma arte produzida para ser recebida pela massa: "a massa distraída (...) faz a obra de arte mergulhar em si, envolve-a com o ritmo de suas vagas, absorve-a em seu fluxo"10. Esta forma de recepção e percepção da obra, modo pelo qual a massa se apropria da obra e a torna próxima ${ }^{11}$, não é contemplativa, individual ou isolada; mas tátil, coletiva e dispersa. A arquitetura é o exemplo mais evidente de arte tátil, cujo sentido se encontra nesse modo de recepção. Há algo de paradoxal nesse modo de recepção, pois o sentido da existência da arte está na recepção coletiva: ela é envolvida pela massa, mas ela também forma a recepção da massa. Essa mudança na ênfase do modo de receber a arte interfere no modo contemplativo de recepção, pois se antes a recepção ótica estava ligada ao modo contemplativo,

\footnotetext{
${ }^{8}$ Ibidem.

${ }^{9}$ Marshall Berman, Tudo que é sólido desmancha no ar, 1986, p. 87.

10 Walter Benjamin, Gesammelte Schriften, 1980, p. 465; A obra de arte na era de sua reprodutibilidade técnica, 1985, p. 193.

${ }^{11}$ A presença das massas no cenário político e social é um dos indícios mais importantes, para Benjamin, das mudanças drásticas nas relações de distância e proximidade nas grandes cidades. A técnica encurta distâncias, e, ao mesmo tempo, aproxima as pessoas, por exemplo, nas ruas, nos locais de trabalho ou mesmo nos meios de transporte. O excesso de proximidade ameaça, como nos indica Baudelaire quando se refere à cidade como uma selva. Essa ameaça não é somente a da proximidade de pessoas que não se conhecemos - diferentemente do que ocorria nas pequenas vilas -, mas é a ameaça que jaz curiosamente mais na destruição da intimidade por excesso de proximidades invasoras que num isolamento espacial e social por excesso de distâncias. Esse excesso de proximidade reforça sentimentos de solidão, de incompreensão e mesmo de hostilidade entre os indivíduos: o excesso de proximidade torna as pessoas cada vez mais estranhas e distantes umas das outras. No entanto, essa ameaça é vencida pelo artifício: a criação de um significado para essa experiência torna possível criar uma outra forma de vida nesse lugar deserto. Sua forma é a da arte e da técnica.
} 
ela agora está determinada ${ }^{12}$ pelo hábito, ou modo de recepção tátil. O motivo pelo qual isso acontece é que

as tarefas impostas ao aparelho perceptivo do homem, em momentos históricos decisivos, são insolúveis na perspectiva puramente ótica: pela contemplação. Elas se tornam realizáveis gradualmente, pela recepção tátil, através do hábito. ${ }^{13}$

Para Benjamin, essas duas formas de recepção da arte - coletiva e distraída - realizam uma tarefa que é necessária para a humanidade. O modo de recepção da arte pela massa impõe-se ao indivíduo, mesmo que este se esquive. Não cabe, portanto, ao indivíduo escolher. A massa, o coletivo, caminha na direção exigida pelas condições dadas. O problema da resistência dos indivíduos é vencido pela força das massas, que não segue necessariamente a melhor direção por conta dessa resistência. Há uma tarefa a ser realizada, há uma força que impele à sua realização.

A arte conseguirá resolver as mais difíceis e importantes (tarefas) sempre que possa mobilizar as massas. É o que ela faz, hoje em dia, no cinema. A recepção através da distração, que se observa crescentemente em todos os domínios da arte e constitui o sintoma de transformações profundas nas estruturas perceptivas, tem no cinema o seu cenário privilegiado. ${ }^{14}$

A arquitetura é o exemplo mais evidente de uma arte que é envolvida pela massa; que é recebida de modo tátil. Vamos nos fixar aqui no papel das novas técnicas, e em particular para Benjamin, o cinema; técnica que, para ele, deixa explícita uma mudança no modo de perceber e receber a arte. Afinal, o cinema não permite a contemplação. E para Benjamin, o surgimento do cinema responde a uma necessidade do próprio aparelho perceptivo: é preciso reaprender a percepção tátil, pois ela nos tirará do labirinto criado pela reflexão segundo os padrões tradicionais.

12 "A recepção tátil se efetua menos pela atenção que pelo hábito. No que diz respeito à arquitetura, o hábito determina em grande medida a própria recepção ótica". (Ibidem, 1980, p. 466; ibidem, 1985, p. 193).

${ }^{13}$ Ibidem, 1980, p. 466; ibidem, 1985, p. 193.

14 "so wird die Kunst deren schwerste und wishtigste nur da angreifen, wo sie Massen mobilisieren kann. Sie tut es gegenwärtig in Film" (Ibidem, 1980, p. 466; ibidem, 1985, p. 194). 
O cinema mostra que a "dominante tátil prevalece no [...] universo da ótica"15. Por mais que se insista sobre a predominância do estímulo visual, nas análises da sociedade moderna, principalmente naquelas que intentam promover as atividades reflexivas, Benjamin insiste que o estímulo visual está dominado pelo tátil. Isto é, ele segue um roteiro já traçado pelo hábito. O cinema não só ilustra tal processo, como permite a sua desestruturação. Segue-se daí que: 1) o cinema permite a percepção das tensões do nosso tempo ao mostrar que a dominante tátil prevalece sobre o universo da ótica; 2) o cinema permite desestruturar esse prevalecimento, não em função da visão, mas em função de uma compreensão diferenciada dos fenômenos da percepção. Se o cinema é a forma de arte "onde a dominante tátil prevalece no próprio universo da ótica"16, a recepção tátil é realizada através do hábito, e é o hábito que determina a recepção ótica.

Tal recepção está marcada pela forma como as construções organizam a utilização do espaço. Benjamin tem em vista nesse texto a forma como o fascismo utiliza-se da crescente massificação: "o fascismo tenta organizar as massas proletárias recém surgidas" ${ }^{\prime 17}$. Benjamin aqui denuncia uma confusão proposital entre reproduzir a massa, isto é, colocá-la como protagonista das imagens, e reprodução em massa. Os comícios gigantescos e espetáculos esportivos fazem parte de um programa de "estetização da vida política". Isso significa a transformação da vida política em imagens nas quais a massa aparece como protagonista, mas na verdade, desempenha apenas o papel de massa - que apoia, aplaude e obedece. Desse modo as imagens de guerra dão um sentido a esse movimento da massa: ali ela se vê grande e cumprindo uma finalidade bela.

A percepção de que a componente ótica é determinada pelo hábito é um conhecimento importante no jogo político encenado pelos nazistas que com sua cenografia transforma a massa em público espectador de suas ações. O cinema

\footnotetext{
${ }^{15}$ Ibidem, 1980, p. 466; ibidem, 1985, p. 194.

16 "tactile Dominant in der Optik selber sich geltend macht" (Ibidem, 1980, p. 466; ibidem, 1985, p. 194).

${ }^{17}$ Ibidem, 1980, p. 467; ibidem, 1985, p. 194.
} 
então nasce com função social ${ }^{18}$ expressa na formulação: "a função social decisiva da arte atual consiste na iniciação da humanidade ao [...] jogo harmonioso" da "natureza" com a "humanidade"19. Para Benjamin, a técnica não tem somente o objetivo de sujeitar a natureza, mas também de produzir essa harmonia. Cumpre, portanto, um papel decisivo como forma de treino e exercício da percepção. Essa é a tarefa do cinema enquanto exercício estético das massas. Trata-se de tomar a sério essa tarefa e proceder de modo a oferecer à massa uma forma de perceber essa dominação do tátil sobre o ótico, e ao mesmo tempo, as possibilidades que a dominante ótica oferece para a experimentação tátil. A recepção tátil das massas nos ensina sobre o modo como se dá a recepção das obras de arte. Aquelas às quais dedicamos uma certa atenção concentrada não são mais do que obras que contemplamos a partir de certos hábitos adquiridos.

Desse modo, para Benjamin, "o cinema se revela [...] o objeto atualmente mais importante daquela ciência da percepção que os gregos chamavam estética"20. Pelo visual ele permite implodir a lógica do hábito. Uma de suas funções sociais mais importantes é a de "criar um equilíbrio entre o homem e o aparelho". E ele realiza essa tarefa não "apenas pelo modo com que o homem se representa diante do aparelho, mas pelo modo com que ele representa o mundo graças a esse aparelho"21. Temos nessa frase não só a afirmação do cinema como uma técnica que, tal como a arquitetura, devolve ao homem seu pensamento em forma material (o cinema, enquanto técnica, torna possível ao homem lidar com o que ele mesmo criou); como também o cinema como produto de uma técnica que permite desfazer aquilo que a própria técnica criada pelo homem construiu. ${ }^{22}$

\footnotetext{
${ }^{18} \mathrm{Cf}$. as três linhas evolutivas na intersecção das quais toda nova forma de arte se encontra, ref. na nota 2 deste trabalho.

19 "Le film sert à exercer l'homme à l'aperception et à la réaction déterminées par la pratique d'un équipement technique dont le rôle dans sa vie ne cesse de croître en importance". (Ibidem, 1980, p. 717).

${ }^{20}$ Ibidem, 1980, p. 466; ibidem, 1985, p. 194.

${ }^{21}$ Ibidem, 1980, p. 460-1; ibidem, 1985, p. 189.

22 "Le but même des révolutions est d'accélérer cette adaptation. Les révolutions sont les innervations de l'élément collectif ou, plus exactement, les tentatives d'innervations de la collectivité qui pour la première fois trouve ses organes dans la seconde technique. Cette technique constitue un système que exige que les forces sociales elementaires soient subjuguées
} 
Se o filme, através de seus grandes planos, de sua ênfase sobre pormenores ocultos dos objetos que nos são familiares, e de sua investigação dos ambientes mais vulgares sob a direção genial da objetiva, estende, por um lado, nossa compreensão sobre as mil determinações de que depende nossa existência, por outro ele vem nos abrir um imenso e insuspeitado campo de ação. ${ }^{23}$

O cinema faz explodir esse universo carcerário, ao possibilitar que a representação da imagem do homem pelo aparelho lhe seja alienada. Essa alienação tem, no entanto, um uso produtivo: ela produz o estranhamento, do mesmo modo que a imagem no espelho. A explosão do universo cotidiano produzida pelo cinema torna possíveis "viagens aventurosas entre as ruínas arremessadas à distância"24: ou seja, permite a percepção de um universo mais amplo do que o do cotidiano, a percepção do sentido dos gestos contidos ou estudados, ou que ocultam sentimentos e anseios reprimidos e/ ou esquecidos. E essa percepção é tanto mais possível quanto mais estudamos, observamos os movimentos - o andar, o gesto de pegar algo. Ela permite o exame daquilo que vemos sem nos darmos conta. O cinema exibe nas telas elementos do sonho coletivo, uma espécie de elixir para as "perigosas tensões que a tecnização [...] engendrou nas massas"25. O cinema, portanto, é tanto produto da inervação dos elementos do coletivo (que cria a técnica) que buscam satisfazer o desejo de uma vida melhor e em harmonia com a natureza, como também produto dessa mesma técnica, visando imunizar as massas contra seus efeitos perniciosos. ${ }^{26}$ Para Benjamin, precisamos rir do que nós mesmos criamos, e isso não é catarse.

As duas características do cinema deverão servir ao homem moderno para libertar-se das exigências que a sociedade capitalista e de consumo se lhes impõe: o cinema nos faz vislumbrar "os mil condicionamentos que determinam nossa

\footnotetext{
pour que puisse s'établir un jeu 'harmonien' entre les forces naturelles et l'homme." (Ibidem, 1980, p. 717). Essa técnica é a que visa liberar o homem do trabalho e com isso estende o seu campo de ação. Ele ainda não sabe orientar-se nesse campo. A apropriação pelo coletivo dessa técnica é que permite esse aprendizado.

${ }^{23}$ Ibidem, 1980, p. 730.

${ }^{24}$ Ibidem, 1980, p. 461; ibidem, 1985, p. 189.

${ }^{25}$ Ibidem, 1980, p. 461; ibidem, 1985, p. 189.

${ }^{26}$ Aqui em total discordância com Adorno, que considera os filmes como produtos que mantêm o espectador no estado de infância emocional.
} 
existência" 27 ao permitir a exploração minuciosa dos objetos e ambientes de nosso cotidiano num alcance que vai muito além do que pode nosso aparelho perceptivo (1) e ao mesmo tempo assegurar-nos "um grande e insuspeitado espaço de liberdade" (2). ${ }^{28} \mathrm{O}$ cinema propicia isso ao registrar nossas ações permitindo-nos perceber que elas resultam de uma montagem minuciosa e detalhada. A implosão do movimento cria a possibilidade de criar outros movimentos, e torna possível a percepção de que nosso mundo é um cenário construído. A câmera funciona como um bisturi cuja intervenção revela o que se passa nos interstícios deste "inconsciente ótico" (que no texto de Benjamin funciona como o que conduz o olhar do mesmo modo que o inconsciente pulsional que conduz nosso pensar consciente). A percepção sensível não pode ser condicionada, ou limitada, àquilo que os olhos vêm. Desse modo a aisthesis de Benjamin aproxima-se, ao mesmo tempo em que se afasta da grega: é certo que há algo além daquilo que nossos olhos vêm, mas esse algo não está no plano do invisível, mas do perceptível.

\title{
2. Flusser: imagens técnicas e nomadismo
}

Em Filosofia da caixa preta, Flusser afirma que uma filosofia da fotografia é necessária para que possa ser uma crítica:

\begin{abstract}
Urge uma Filosofia da fotografia para que a práxis fotográfica seja conscientizada. A conscientização de tal práxis é necessária porque sem ela jamais captaremos as aberturas para a liberdade na vida do funcionário dos aparelhos. Em outros termos: a filosofia da fotografia é necessária porque é reflexão sobre as possibilidades de se viver livremente num mundo programado por aparelhos. ${ }^{29}$
\end{abstract}

No capítulo dedicado ao aparato, ou aparelho, como foi traduzido para o português, Flusser, após uma digressão sobre a origem da palavra apparatus o

\footnotetext{
${ }^{27}$ Ibidem, 1980, p. 461; ibidem, 1985, p. 189.

${ }^{28}$ Ibidem, 1980, p. 461; ibidem, 1985, p. 189.

${ }^{29}$ Vilém Flusser, Filosofia da caixa preta, 2002, p. 76. Na versão em inglês: "A philosophy of photography must reveal the fact that there is no place for human freedom within the area of automated, programmed and programming apparatuses, in order finally to show a way in which it is nevertheless possible to open up a space for freedom." (Vilém Flusser, Towards a philosophy of photography, 1983, p. 81).
} 
define como "a thing that lies in wait or in readiness for something, and a 'preparatus' would be a thing that waits patiently for something. The photographic apparatus lies in wait for photography"30.

O aparato ao qual o texto se refere é o aparelho fotográfico. Porém, pelo modo como define a fotografia, o aparelho fotográfico e seus derivados, podemos perceber que Flusser não está vinculado somente a um aparelho, mas também à sociedade que o produz e na qual as imagens fotográficas têm um papel. ${ }^{31}$ Esse mundo é o da revolução industrial que evoluiu para colocar os homens a serviço das máquinas. Assim, a câmera fotográfica é também uma máquina que coloca o homem a seu serviço. Os instrumentos produzidos pelo momento que se segue à revolução industrial - pós-industrial - não são mais extensões do corpo humano, mas aparelhos cujas funções e possibilidades múltiplas de uso adquiriram um poder sobre os homens. São objetos programados, automáticos, que realizam funções complexas que independem dos seres humanos que os operam.

Algumas de suas afirmações o levam a ter uma posição pessimista diante da introdução das técnicas. Por exemplo a possibilidade grande mas limitada de ação que as máquinas oferecem, que pode ser estendida a todo e qualquer objeto, seja produzido ou natural. Os objetos produzidos fazem parte da cultura, e refletem em si os valores dessa cultura. Por mais que coloquemos e discutamos

\footnotetext{
${ }^{30}$ A tradução para o português está ligeiramente diferente. Cito ainda outro trecho da versão em inglês que acrescenta mais três conceitos: temos, então: aparelho, jogo, programa, informação. "Apparatuses are playthings that repeat the same movements over and over again. Programs are games that combine the same elements over and over again. Pieces of information are improbable states that break away again and again from the tendency to become probable only to sink back into it again and again. In short: With these four basic concepts, we no longer find ourselves in the historical context of the linear, in which nothing is repeated and everything has a cause yielding consequences." (Vilém Flusser, Towards a philosophy of photography, 1983, p. 77). ${ }^{31}$ Flusser, em O universo das imagens técnicas: o elogio da superficialidade, publicado em 2012 pela Annablume, estende o universo das imagens para as imagens produzidas por computador, para o cinema, a mídia, os aparatos da comunicação e o próprio processo da comunicação. Assim como a obra citada na nota 27, que não se constituiu em um livro sobre fotografia, esta sua obra é um conjunto de estudos "das consequências sócio-ambientais (não apenas na natureza e na sociedade, mas sobretudo na cultura) geradas pela proliferação das tecno-imagens" (Baitello, prefácio a Vilém Flusser, O universo das imagens técnicas, 2012, p. 8).
} 
questões acerca do que envolve o aparato, o fato de ele ser ou não um instrumento estende nossa visão.

Sem dúvida, trata-se de objetos produzidos, isto é, objetos trazidos da natureza para o homem. $\mathrm{O}$ conjunto de objetos produzidos perfaz a cultura. Aparelhos (Apparatuses) fazem parte de determinadas culturas, conferindo a estas certas características. Não há dúvida que o termo aparelho é utilizado, às vezes, para denominar fenômenos da natureza, por exemplo, aparelho digestivo, por tratar-se de órgãos complexos que estão à espreita de alimentos para enfim digeri-los. ${ }^{32}$

Porém Flusser acrescenta que o uso da palavra para objetos da natureza é um uso metafórico transportado de uma esfera para outra. Contudo, pode-se acrescentar que não somente aparelhos mecânicos, mas o aparelho digestivo, por exemplo, também impõe limites de possibilidades. Ou seja, tais limitações referem-se a todo e qualquer ser. Flusser tem uma expectativa de liberdade que parece não corresponder à realidade. Ao final do livro, afirma que a tarefa da filosofia da fotografia é apontar o caminho da liberdade, e que ela é a única revolução possível. Flusser parece viver sob o fantasma da liberdade total e das possibilidades infinitas, lamentando que vivamos hoje num mundo programado por aparelhos. Tal afirmação nos parece bastante estranha, já que os aparelhos são programados pelos próprios humanos.

Apesar de seu pessimismo, Flusser considera que aquele que utiliza o aparelho pode jogar com ele; ou seja, pode usar a programação para produzir uma imagem que não se limite a ela. Porém, a questão que mais enfatizada é a da mudança operada por esta sociedade, que qualifica como pós-industrial e da informação ${ }^{33}$ : nela, o simbólico reina sobre o material, e isso se deve principalmente ao fato de que a grande mudança ocorrida nos últimos tempos foi

32 "They are indubitably things that are produced, i.e. things that are pro-duced (brought forward) out of the available natural world. The totality of such things can be referred to as culture. Apparatuses are part of a culture, consequently this culture is recognizable in them. It is true that the word apparatus is also occasionally applied to natural phenomena, e.g. when speaking of the hearing apparatus of animals." (Vilém Flusser, Towards a philosophy of photography, 1983, p. 22).

${ }^{33}$ Vilém Flusser, Filosofia da caixa preta, 2002, p. 29-30. 
a invenção das imagens técnicas. As imagens transmutam o mundo, transferemno para a superfície:

\begin{abstract}
Imagens são superfícies que pretendem representar algo. Na maioria dos casos, algo que se encontra lá fora, no espaço e no tempo. As imagens são, portanto, resultado do esforço de se abstrair duas das quatro dimensões espácio-temporais, para que se conservem apenas as dimensões do plano. ${ }^{34}$
\end{abstract}

Para Flusser, as principais características das imagens - a possibilidade de interpretação de seus símbolos, sua equivocidade, o olhar girando em círculos - a tornam um elemento que impede a compreensão do mundo. Elas se colocam entre o homem e o mundo, são mediações, e por esse motivo o afastam de uma forma de perceber que o colocaria em contato com a percepção imediata. A imagem acaba por se prestar a uma relação mágica, confundindo-se com a realidade. Esse é para ele o momento em que a idolatria do texto é substituída pela idolatria da imagem. Podemos então pensar: é uma idolatria que substitui outra, nada de novo. Mas para Flusser a nova idolatria aponta para um problema presente na era "póshistórica" e "pós-ideológica"35: trata-se de uma "crise da história que não pode mais ser solucionada"36. Trata-se de compreender, para Flusser, que o surgimento das imagens técnicas vem preencher um vazio deixado pela narrativa. "Seu trabalho era o de 'tornar as imagens compreensíveis novamente, [...] superar a crise da história"'37.

Norval Baitello ${ }^{38}$ nos descreve as três catástrofes, sendo que o que caracteriza os degraus dessas catástrofes é o avanço da abstração. O segundo degrau "éalcançado pela transformação das imagens em pictogramas, ideogramas e letras, que abrem ao homem o caminho para o universo da escrita (e de sua

\footnotetext{
${ }^{34}$ Ibidem, 2002, p. 7.

${ }^{35}$ Não cabe aqui discutir a questão dessas classificações feitas por Flusser acerca da nossa contemporaneidade, e repetidas por Amelunxen (cf. nota 29). Trataremos desse tema em outro momento.

${ }^{36}$ Hubertus von Amelunxen, Posfácio, 2011, p. 93-94.

${ }^{37}$ Ibidem, 2011, p. 94.

${ }^{38}$ Norval Baitello, Vilém Flusser e a terceira dor do homem ou as dores do Espaço, a fotografia e o vento, 2006, p. 4-5.
} 
decifração, a leitura)"39. O terceiro degrau marca, portanto, a transformação das imagens planas em escrita linear. Essa mudança influencia na concepção de tempo: antes era circular; o tempo do eterno-retorno. Agora, é linear. Como vimos, o surgimento das imagens técnicas vem substituir esse "pensamento linear e conceitual $^{\prime 40}$ ancorado na escrita. Porém as imagens técnicas não representam um retorno às imagens tradicionais, mas resultam, ao contrário, do avanço da abstração e da crise da palavra escrita. Elas representam um passo além nesse processo. $\mathrm{O}$ fato de serem formadas por pequenos grãos que vão produzir a forma final é já para Flusser indicativo de que são uma "construção conceitual"11: são formadas de pequenos grãos, de "pedrinhas minúsculas se aglutinam no espaço plano, formando a ilusão de imagens" ${ }^{\text {"42 }}$. Não são um retorno ao aspecto mágico da imagem tradicional, mas criam a ilusão deste ao colocarem-se como imagens da realidade. Segundo Baitello ${ }^{43}$ :

\begin{abstract}
Vilém Flusser reserva à fotografia um status especial dentre as imagens técnicas: por sua qualidade germinativa da nova era da imagem, pelo resgate da magia após a "desmagicização" promovida pela escrita, pelo retorno à circularidade do olhar, pela volta do tempo do eterno retorno e, sobretudo, por ser ela a inauguração das tecno-imagens, imagens sintéticas compostas por granulação e por cálculos - vale dizer, por ser a fotografia uma imagem que nãoé imagem.
\end{abstract}

O terceiro degrau da catástrofe completa-se então com o advento das imagens técnicas, com especial ênfase à fotografia, pois esta é produto de um aparelho que programa a imagem que capta (e só capta as imagens que programa). ${ }^{44}$ Para Flusser, o valor destes aparelhos não mais reside neles, mas no programa implantado que conduz a ação do operador. Com isso indica a vitória do aparelho sobre o homem, numa afirmação que contradiz a previsão benjaminiana de que o homem pode manter-se como ele mesmo diante do aparelho. Em relação à fotografia, diz Flusser: "No fundo não somos nós que a manipulamos, é ela quem

\footnotetext{
${ }^{39}$ Ibidem, 2006, p. 4.

40 Ibidem, 2006.

${ }^{41}$ Ibidem, 2006, p. 5.

42 Ibidem, 2006.

${ }^{43}$ Ibidem, 2006.

${ }^{44}$ Ibidem, 2006.
} 
nos manipula"45 e nos conduz. A terceira catástrofe, segundo Baitello, seria a "que tornou inabitáveis as habitações, empurrando o homem a seguir novamente o seu velho companheiro nômade, o vento, o 'spiritus', o 'pneuma', o 'ruach', em busca do momento germinal do sopro que deu vida ao barro inerte" 46 . Desse modo, assim como Amelunxen, relaciona o pensamento de Flusser à sua condição de nômade, de emigrado sem raiz e sem chão, que reflete "a insegurança básica do destino humano"47.

Em $O$ universo das imagens técnicas: o elogio da superficialidade, Flusser avança seu diagnóstico ao indicar como resultado da produção de imagens técnicas uma "escalada da abstração". Esse aspecto é o que diferencia as imagens tradicionais das imagens técnicas. O efeito disso é indicado por ele:

Partindo das imagens técnicas atuais, podemos reconhecer nelas duas tendências básicas diferentes. Uma indica o rumo da sociedade totalitária, centralmente programada, dos receptores das imagens e dos funcionários das imagens; a outra indica o rumo para a sociedade telemática, dialogante dos criadores das imagens e dos colecionadores das imagens. As duas formas parecem fantásticas para nós, embora a primeira utopia tenha características negativas, e a segunda positivas. ${ }^{48}$

Como já havia anunciado em Filosofia da caixa preta, Flusser entende que as imagens são produtos da cultura, dos aparelhos produzidos pelo homem. Enquanto que na obra anterior Flusser via um caminho de perda e de distanciamento do homem em relação a algo que ficou na distância temporal, em O universo das imagens técnicas, apesar do subtítulo ("O elogio da superficialidade"), Flusser indica duas possibilidades que a proliferação de imagens cria. Apesar de enfatizar a "obediência a um programa ou roteiro previamente inscrito em esfera infra- ou supra-individual", considera que a proliferação de imagens possa ter um lado positivo, possa resultar numa utopia positiva.

\footnotetext{
${ }^{45}$ Vilém Flusser, Towards a philosophy of photography, 1983, p. 62.

${ }^{46}$ Norval Baitello, Vilém Flusser e a terceira dor do homem ou as dores do Espaço, a fotografia e o vento, 2006, p. 6.

${ }^{47}$ Hubertus von Amelunxen, Op. Cit., 2011, p. 86.

${ }^{48}$ Vilém Flusser, O universo das imagens técnicas, 2012, p. 14.
} 


\section{Agamben}

Agamben compartilha da concepção de Flusser em vários pontos. Em primeiro lugar, apesar de Flusser chamar de apparatus a máquina ou aparelho, entende, como vimos, que tal aparelho está vinculado à sociedade que o produz, e, portanto, é o produto de um modo de vida. Por sua vez, Agamben expõe a noção de dispositivo a partir de Foucault como um conjunto de elementos heterogêneos, tais como "discursos, instituições, formas arquitetônicas, decisões reguladoras, leis, medidas administrativas, proposições científicas, proposições filosóficas, morais e filantrópicas - em resumo - o dito tanto quanto o não dito"49. A reflexão de Agamben retoma o uso do termo por Foucault, no sentido de enfatizar seu uso como aquilo em que, e através do que, "se realiza uma pura atividade de governo sem nenhum fundamento no ser. Por isso devem sempre implicar um processo de subjetivação, isto é, devem produzir o seu sujeito"50. Também há um encontro aqui com Flusser e Benjamin, pois para ambos - e também para Agamben e Foucault -, as técnicas e a tecnologia podem ser e são utilizadas para controlar e dominar, formar um público cativo para o espetáculo do qual participam os dirigentes (por exemplo, o caso do nazismo em Benjamin, mas também das democracias modernas). Antes de continuarmos com a digressão de Agamben, cabe aqui uma nota sobre a tradução do termo francês dispositif para apparatus na edição inglesa, o que poderia favorecer uma aproximação de Agamben com Flusser nesse ponto. Agamben ${ }^{51}$ afirma que não está satisfeito com essa tradução e propõe o termo dispositor, um termo ligado à astrologia, em seu lugar, cuja definição segundo o English Oxford Dictionary ${ }^{52}$ é "the planet which rules the sign in which another planet is located in a particular chart". O próprio Agamben caracteriza sua tradução como monstruosa, porém sua preocupação com a

\footnotetext{
${ }^{49}$ Michel Foucault apud Giorgio Agamben, O que é o contemporâneo? e outros ensaios, 2009, p. 38.

50 Ibidem.

${ }^{51}$ Giorgio Agamben, What is a dispositive?, 2005 (aula 1).

52 Disponível em: https://en.oxforddictionaries.com/definition/dispositor. Acesso em: 29 abr. 2019.
} 
terminologia o faz escolher uma palavra que não possa ser confundida no seu sentido. ${ }^{53}$

Ao afastar-se da filologia foucaultiana, Agamben apresenta uma divisão dos seres em seres vivos e dispositivos que corresponde, por um lado, à ontologia das criaturas, e, por outro, aos dispositivos que teriam por função guiar os seres na direção do bem ${ }^{54}$, e, nesse sentido, tudo o que foi produzido pelo homem, desde manicômios a escolas e fábricas, da literatura à filosofia, da caneta ao cigarro, é um dispositivo. O sujeito é ele mesmo um ser que resulta da relação entre seres e dispositivos. Até aqui, Agamben parece estar usando as divisões para melhor compreender a ação do dispositivo; porém, ao final do texto, enfatiza a dessubjetificação promovida pelos dispositivos como computadores e celulares, considerando tais aparelhos como a última forma de não subjetividade e de controle.

Tal como Flusser em relação aos aparatos, Agamben considera que os dispositivos determinam formas de comportamento. Por isso, defende que o "dispositivo é, antes de tudo, uma máquina que produz subjetivações e somente enquanto tal é também uma máquina de governo"55. O dispositivo determina as ações e escolhas do sujeito, que segundo Agamben tornam suportável a perda das relações consigo mesmo e com os outros, substituída pela relação com o dispositivo. Isso se deve à possibilidade que essas relações ofertam de um gozo, da realização de um desejo. Para Agamben, "na raiz de cada dispositivo está, desse modo, um desejo demasiadamente humano de felicidade, e a captura e a subjetivação deste desejo, numa esfera separada, constituem a potência específica do dispositivo"56. Assim, a estratégia adotada para combater o dispositivo "não pode ser simples"57; deve consistir na "liberação e captura" daquilo que foi tomado

\footnotetext{
53 Segundo o mesmo dicionário, a palavra apparatus significa "The technical equipment or machinery needed for a particular activity or purpose". Disponível em: https://en.oxforddictionaries.com/definition/apparatus. Acesso em: 28 abr. 2019.

54 Giorgio Agamben, O que é o contemporâneo? e outros ensaios, 2009, p. 40.

55 Ibidem, 2009, p. 46.

${ }^{56}$ Ibidem, 2009, p. 44.

${ }^{57}$ Ibidem.
} 
pelo dispositivo, para ser trazido para o uso comum. Chama esse processo de "profanação" ${ }^{58}$, conceito cuja origem encontra-se no direito romano e que consiste no ato de restituir ao uso humano o que foi consagrado aos deuses. $\mathrm{O}$ termo vem da esfera religiosa: ela é quem promove essa separação do que é sagrado em relação ao que é profano por meio de pequenos rituais. A profanação indica que o que foi separado pode ser restituído à esfera profana. "Profanação é o contradispositivo que restitui para o uso comum o que o sacrifício tinha separado e dividido"59.

Agamben afirma então que o capitalismo "e outras formas modernas de poder" levam esse processo de separação "que definem a religião" ao extremo. E que na sociedade disciplinar, conforme Foucault, o aparato visa criar "corpos dóceis"60 que se veem como sujeitos dentro desse processo de dessubjetificação. Tais processos são máquinas de governo que produzem sujeitos dóceis, que se submetem aos ditames do aparato. A profanação seria como um jogo, no qual esferas arrestadas pelo aparato seriam libertas desse domínio, podendo então ser usadas livremente pelos homens. Esta afirmação pode ser contrastada com a que aparece em Profanações. Neste, Agamben afirma que esse jogo pode ser ilusório. Podemos pensar em jogá-lo acreditando que de fato conseguimos liberar forças a nosso favor, mas o capitalismo extremo pode criar formas de retomar o espaço conquistado pela profanação: "Se profanar significa restituir ao uso comum o que havia sido separado na esfera do sagrado, a religião capitalista, na sua fase extrema, está voltada para a criação de algo absolutamente Improfanável"ø1.

Por isso, Agamben, em O que é um dispositivo?, enfatiza a urgência da profanação dos aparatos, pois o "triunfo da oikonomia (...) reduziu a política a uma pura atividade de governo que visa somente sua própria reprodução"62. Diante dela, qualquer um que possa escapar ao processo de dessubjetivação é

\footnotetext{
58 Ibidem, 2009, p. 44-45.

59 Ibidem, 2009, p. 45.

60 Ibidem, 2009, p. 46. Inclusive todas as citações que antecedem a esta neste parágrafo.

${ }^{61}$ Giorgio Agamben, Profanações, 2007, p. 71.

62 Giorgio Agamben, O que é o contemporâneo? e outros ensaios, 2009, p. 49.
} 
caracterizado como um "terrorista virtual"63. Assim, Agamben afirma apresentarse diante de nós uma catástrofe diferente da catástrofe do fim da história ou de seu vazio, anunciada por Flusser: a catástrofe é o girar incessante da máquina sem destino.

Agamben discorda daqueles que consideram que o problema da tecnologia "se reduz àquele de seu uso correto"64. É possível que não haja mesmo um "uso correto", ou uso que se oponha a esses efeitos deletérios, pois segundo sua definição de aparato, os efeitos se devem ao próprio aparato. Os problemas da sociedade contemporânea apontados por ele - inércia e dessubjetivação - não se devem somente aos aparelhos e seu uso, mas, pode-se dizer com Schelling, a uma crise espiritual sem precedentes que não vê na técnica e no uso dos aparelhos uma forma de iniciação da humanidade ao jogo harmonioso da natureza com a humanidade, tal como pensa Benjamin.

\section{Algumas considerações finais}

Agamben afirma, a certa altura de O que é um dispositivo?, seguir um princípio metodológico (podemos dizer, este também um dispositivo), que é o de seguir um conceito até sua capacidade de desenvolvimento, e, portanto, de não forçar a interpretação para além das regras da hermenêutica. Por isso, num certo ponto tem que parar de seguir a interpretação, para seguir por conta própria. ${ }^{65}$

É o que vamos fazer aqui, arriscando-nos numa linha na qual pretendemos identificar alguns pontos de congruência e de distanciamento entre os autores apresentados. Porém, apontar esses pontos é, para nós, uma tentativa de identificar até que ponto esses conceitos podem nos auxiliar na reflexão sobre o papel das técnicas num sentido amplo.

\footnotetext{
${ }^{63}$ Ibidem, 2009, p. 49.

${ }^{64}$ Ibidem, 2009, p. 48.

${ }^{65}$ Ibidem, 2009, p. 39-40.
} 
Se a hominização do homo sapiens ${ }^{66}$ relaciona-se intimamente com a criação de dispositivos, ou, de maneira mais geral, com a utilização de técnicas para melhorar suas chances de sobrevivência (desde o domínio do fogo, da utilização de materiais para construir casas e utensílios, da produção de sons que visavam comunicar), é impossível separar o momento no qual ele é um ser produzido por um dispositivo. Ele produz os dispositivos para seu uso.

A questão importante para os três autores é a de diagnosticar na sociedade contemporânea a função desses aparelhos/técnicas/dispositivos, e de como podemos lidar com eles de maneira que permaneçamos nós mesmos. Benjamin, em algum momento de seu projeto Paris Capital do século XIX, e em seus textos sobre Baudelaire, caracteriza o sistema econômico da época (de Baudelaire, mas também da sua própria) como capitalismo produtor de mercadorias, entendendo esse momento não só a partir do aspecto econômico, mas também segundo o aspecto filosófico - que transforma o mundo dos seres em mercadorias. ${ }^{67}$ Agamben e Flusser compreendem a época (anos 1980 a 2000) como a de uma sociedade pós-industrial e pós-histórica. Para Flusser, este segundo aspecto significa o fim das narrativas, enquanto para Agamben indica a ideia de algo que gira sem sair do lugar. Afinal, todos os dispositivos reproduzem indefinidamente o funcionamento dessa sociedade. Em Flusser, a tarefa urgente é a de compreender o processo no qual entramos como uma auto-referência infinita por meio das imagens, o que poderia render a possibilidade de apontar para uma utopia positiva. Para Agamben, "o problema da profanação (...) é urgente"68, isto é, o de não mais permitir a inclusão de todas as práticas na esfera no poder. Ao afirmar que o ponto de fuga da política é o ingovernável, aponta para o que foi abandonado no processo de hominização: aquilo que não se deixa governar.

\footnotetext{
${ }^{66}$ Ibidem, 2009, p. 43.

${ }^{67}$ Segue aqui o diagnóstico de G. Lukács, em História e Consciência de Classe, e Karl Korsch, em Marxismo e Filosofia, 1977, que ele teria lido na época.

${ }^{68}$ Ibidem, 2009, p. 51.
} 
Creio que está nesse processo uma possível resposta: os dispositivos, as técnicas, realizam um sonho humano, uma utopia. Repetimos aqui parte do texto da nota 18, em que diz Benjamin:

O próprio objetivo das revoluções é acelerar essa adaptação. As revoluções são as enervações do elemento coletivo ou, mais exatamente, as tentativas de as enervações da coletividade que, pela primeira vez, fazem encontrar seus orgãos entre a segunda técnica. ${ }^{69}$

Significa que as técnicas, os dispositivos, não foram criados para se impor sobre nós. Não podem ser um modo de identificarmos o ser, mas uma maneira indireta, lateral, de colocarmos nosso ser no mundo, criando meios de lidarmos com as dificuldades e as tensões.

\section{Referências}

ADORNO, T. Fetichismo na música e regressão da audição. In: Os pensadores (Coleção). São Paulo: Abril, 1975. p. 173-199.

AGAMBEN, G. O que é um dispositivo. In: AGAMBEN, G. O que éo contemporâneo? e outros ensaios. Trad. Vinícius N. Honesko. Chapecó/SC: Argos, 2009. p. 27-51.

AGAMBEN, G. What is an apparatus? And other essays. Trad. David Kishik \& S. Pedatella. Stanford: Stanford University Press, 2009a.

AGAMBEN, G. Profanações. São Paulo: Boitempo, 2007.

AGAMBEN, G. What is a dispositive? Aulas em vídeo da European Graduate School, 2005. Disponível em:

https://www.youtube.com/watch?v=ua7ElsQFZPo (aula 1); disponível em:

69 Walter Benjamin, Gesammelte Schriften, 1980, p. 717. Tradução minha: "Le but même des rèvolutions est d'accélérer cette adaptation. Les revolutions sont les innervations de l'element collectif ou, plus exactement, les tentatives de l'innervation de la collectivité qui pour la prémiére fois trouve ses organs dans la seconde techinique". 
https://www.youtube.com/watch?v=MNWie3YqmSY (aula 2). Acesso em: 28 abr. 2019.

AMELUNXEN, H. Posfácio. In: FLUSSER, V. Filosofia da caixa preta. São Paulo: Annablume, 2011.

BAITELLO, N. Vilém Flusser e a terceira dor do homem ou as dores do Espaço, a fotografia e o vento. Flusser Studies, 3 nov. 2006. Disponível em: http://www.flusserstudies.net/archive/flusser-studies-03-november-2006. Acesso em: 28 abr. 2019.

BAITELLO, N. Prefácio. A escalada da abstração. In: FLUSSER, Vilém. O universo das imagens técnicas: elogio da superficialidade. São Paulo: Annablume, 2012. p. 7-10.

BENJAMIN, Walter. A obra de arte na era de sua reprodutibilidade técnica. In: BENJAMIN, Walter. Magia e técnica, arte e política. Trad. Sérgio Paulo Rouanet. Prefácio Jeanne Marie Gagnebin. São Paulo: Brasiliense, 1985. p. 165-196. (Obras escolhidas, volume 1).

BENJAMIN, Walter. Das Kunstwerk im Zeitalter seiner technischen Reproduzierbarkei. In: BENJAMIN, Walter. Gesammelte Schriften. Vol. I. Frankfurt: Suhrkamp Verlag, 1980. Erste Fassung, p. 431-469; Zweite Fassung, p. 471-508.

BENJAMIN, Walter. L' oeuvre d'art à l'époque de sa reproduction mecanisée. In: BENJAMIN, Walter. Gesammelte Schriften. Vol. I. Frankfurt: Suhrkamp Verlag, 1980. p. 709-739.

BENJAMIN, Walter. Experiência e Pobreza. In: BENJAMIN, Walter. Magia e técnica, arte e política. Trad. Sérgio Paulo Rouanet. Prefácio Jeanne Marie Gagnebin. São Paulo: Brasiliense, 1985. p. 114-119. (Obras escolhidas, volume 1). 
BENJAMIN, Walter. A Paris do segundo império. In: BENJAMIN, Walter.

Charles Baudelaire, um lírico no auge do capitalismo. Trad. José Martins Barbosa \& Hemerson Alves Baptista. São Paulo: Brasiliense, 1989. p. 9-101. (Obras escolhidas, volume 3).

BENJAMIN, Walter. Das Paris des Second Empire bei Baudelaire. In: BENJAMIN, Walter. Gesammelte Schriften. Vol. I. Frankfurt: Suhrkamp Verlag, 1980.

BERMAN, Marshall. Tudo que é sólido desmancha no ar: a aventura da modernidade. Trad. Carlos Felipe Moisés \& Ana Maria L. Ioriatti. São Paulo: Companhia das Letras, 1986.

FLUSSER, Vilém. Towards a philosophy of photography. London: Reaktion Books, 1983.

FLUSSER, Vilém. Filosofia da caixa preta. São Paulo: Relume Dumará, 2002.

FLUSSER, Vilém. O universo das imagens técnicas: elogio da superficialidade. São Paulo: Annablume, 2012. p. 7-10.

GOETZ, Benoît. La dislocation. Architecture et Philosophie. Paris: Les éditions de la Passion, 2002.

SAINT GIRONS, Baldine. L'acte esthétique. Paris: Klincksieck, 2008.

\section{Referência para citação deste artigo}

FERRARI, Sônia. Cinema e fotografia: as técnicas e suas ambiguidades em Benjamin, Flusser e Agamben. Revista PHILIA | Filosofia, Literatura \& Arte, Porto Alegre, volume 1, número 2, p. 526 - 547, outubro de 2019. 